\title{
La sociedad del coste marginal cero. El internet de las cosas, el procomún colaborativo y el eclipse del capitalismo (2014). Jeremy Rifkin. Editorial Paidós Ibérica, Madrid.
}

\section{Por Jaime Bailón (Universidad de Lima)}

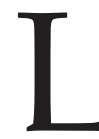

a comunicación masiva ha estado estrechamente ligada a la modernidad capitalista. No podemos pensar la comunicación sin establecer una reflexión en torno a las profundas trasformaciones que vienen experimentando la economía y la tecnología contemporáneas.

Jeremy Rifkin, profesor de Wharton School (University of Pennsylvania), analiza estos cambios y señala que estamos entrando a un nuevo estadio económico: el procomún colaborativo, resultado de la revolución informática y de profundas transformaciones económicas y políticas. En esta etapa lo que adquiere mayor valor no es la producción de bienes físicos sino la experiencia; las transacciones económicas circulan a la velocidad de la luz y la relación entre productores y consumidores es directa, sin intermediarios. El libro trabaja los lineamientos de esta nueva economía y analiza sus repercusiones en los diversos campos de la actividad económica y del conocimiento.

Los saberes de la modernidad vienen experimentando una transformación disruptiva. La ciencia cartesiana newtoniana ha resultado insuficiente para analizar los caóticos procesos sociales y económicos contemporáneos. Su visión reduccionista, búsqueda incesante de regularidades e imposibilidad de aprender fenómenos irreversibles, hace imprescindible la construcción de mecanismos cognoscitivos de mayor complejidad. Así mismo, las formas de transmisión del conocimiento superan los muros de la escuela e invaden las redes digitales. Los cursos MOOC (acrónimo en inglés de Massive Open Online Course) son la expresión de esta transformación de la educación. Sus costos operativos respecto a la educación tradicional son mínimos y sus alcances de cobertura aventajan de manera exponencial a los de la escuela convencional.

Esta posibilidad de acceso y colaboración viene invadiendo también los territorios de la producción económica. El internet de las cosas y las impresoras 3D hacen que el costo de fabricación de objetos descienda 
de forma radical, otro tanto ya viene ocurriendo con las formas de acceso a la energía. En lugar de recurrir a plantas centrales manejadas por grandes corporaciones, estas ahora son descentralizadas y autogestionadas por pequeñas comunidades.

El término "utopística" resulta el más adecuado para calificar las tesis del libro de Rifkin. Si bien se trata de alternativas difíciles de implantar, resultan totalmente plausibles. Su dificultad de aplicación radica no tanto en su imposibilidad tecnológica sino en la enorme resistencia de las grandes corporaciones del capitalismo fordista. Lo que hace viable la apuesta de Rifkin es que todo este proceso de disrupción producto del cambio tecnológico viene precedido por transformaciones políticas y económicas que también este libro analiza con exhaustividad.

Se trata, sin lugar a dudas, de un texto de lectura obligatoria para todos los interesados en adquirir un conocimiento sistémico de las implicancias de la revolución tecnológica digital. 